\title{
Idiopathic pulmonary fibrosis: survival in population based and hospital based cohorts
}

\author{
Douglas W Mapel, William C Hunt, Rose Utton, Kathy B Baumgartner, \\ Jonathan M Samet, David B Coultas
}

\begin{abstract}
Background-To ascertain whether findings from hospital based clinical series can be extended to patients with idiopathic pulmonary fibrosis (IPF) in the general population, the survival of patients with IPF in a population based registry was compared with that of a cohort of patients with IPF treated at major referral hospitals and the factors influencing survival in the population based registry were identified.
\end{abstract}

Methods-The survival of 209 patients with IPF from the New Mexico Interstitial Lung Disease Registry and a cohort of 248 patients with IPF who were participating in a multicentre case-control study was compared. The determinants of survival for the patients from the Registry were determined using life table and proportional hazard modelling methods.

Results-The median survival times of patients with IPF in the Registry and case-control cohorts were similar (4.2 years and 4.1 years, respectively), although the average age at diagnosis of the Registry patients was greater $(71.7$ years versus 60.6 years, $p<0.01)$. After adjusting for differences in age, sex, and ethnicity, the death rate within six months of diagnosis was found to be greater in the Registry patients (relative hazard (RH) $6.32,95 \%$ CI 2.19 to 18.22 ) but more than 18 months after diagnosis the death rate was less (RH 0.35 , 95\% CI 0.19 to 0.66 ) than in the patients in the case-control study. Factors associated with poorer prognosis in the Registry included advanced age, severe radiographic abnormalities, severe reduction in forced vital capacity, and a history of corticosteroid treatment.

Conclusions-The adjusted survival of patients with IPF in the general population is different from that of hospital referrals which suggests that selection biases affect the survival experience of referral hospitals.

(Thorax 1998;53:469-476)

Keywords: idiopathic pulmonary fibrosis; survival

Idiopathic pulmonary fibrosis (IPF)/ cryptogenic fibrosing alveolitis is a chronically progressive interstitial lung disease which results in severe disability and death in the majority of cases. ${ }^{1} \mathrm{IPF}$ is the most common interstitial lung disease with an incidence of approximately 15 per 100000 per year. ${ }^{2}$ Because difficult decisions must be made regarding treatment and the patient's anticipated decline in quality of life, both physicians and patients need valid prognostic information. Reports of case series estimate that median survival for IPF is 3-5 years; however, there is uncertainty in these estimates due to the differences in the study populations and their relatively small sizes, the difficulty in establishing onset of the disease, and differences in the rate of disease progression. ${ }^{3}$ The factors that have been associated with survival in IPF include age at onset of symptoms and diagnosis, ${ }^{4-7}$ sex, ${ }^{458}$ duration of symptoms, ${ }^{6} 910$ the severity of chest radiographic abnormalities, ${ }^{4-6811}$ pulmonary function impairment, ${ }^{68911-13}$ the degree of active alveolar inflammation, ${ }^{4-1114}$ and response to corticosteroid or immunosuppressive therapy. ${ }^{6} 9^{13-15}$ However, because this information is based mainly on the case-series experience of referral centres, it may represent a biased sample of all patients with IPF. We do not know if the findings of these studies can be extended to patients seen in the community with IPF.

The New Mexico Interstitial Lung Disease (ILD) Registry was established in 1988 to describe the occurrence of interstitial lung diseases, including IPF, in Bernalillo County, New Mexico (1990 population 480577$){ }^{2}$ Data from this Registry, as compared with case series data, can be used to describe the natural history of unselected IPF patients, the incidence of disease, and the treatment of IPF in the general population. To determine whether selection biases affect the survival of patients with IPF seen in referral centres we compared the survival of 209 incident cases of IPF identified by the New Mexico ILD Registry with that of 248 patients with IPF who were ascertained through referral centers as participants in a case-control study on aetiology. ${ }^{16}$ This report also presents an analysis of factors affecting the survival of patients with IPF in the population based Registry.

\section{Methods}

THE NEW MEXICO ILD REGISTRY

The New Mexico ILD Registry was established in 1988 to describe the prevalence and incidence of interstitial lung diseases in a population based cohort. $^{2}$ All pulmonary physicians, internists, family practitioners, and other physicians in Bernalillo County, New Mexico who encountered patients with interstitial lung diseases were solicited for cases; in 
Table 1 Demographic and clinical characteristics of patients with idiopathic pulmonary fibrosis (IPF) in the population based New Mexico (NM) ILD Registry and the hospital based cohort

\begin{tabular}{|c|c|c|}
\hline Characteristic & $\begin{array}{l}\text { NM ILD Registry } \\
(n=209)\end{array}$ & $\begin{array}{l}\text { Hospital based } \\
\text { cohort }(n=248)\end{array}$ \\
\hline Mean (SD) age & $71.7(12.3)$ & $60.6(10.4)$ \\
\hline \multicolumn{3}{|l|}{ Sex $(\%)$} \\
\hline Male & 55.0 & 60.1 \\
\hline Female & 45.0 & 39.9 \\
\hline \multicolumn{3}{|l|}{ Ethnicity $(\%)^{\star}$} \\
\hline Non-Hispanic White & 61.2 & 85.9 \\
\hline Hispanic & 23.0 & 4.8 \\
\hline Black & 1.4 & 7.3 \\
\hline Native American & 1.9 & 0.8 \\
\hline Other & 12.4 & 1.2 \\
\hline \multicolumn{3}{|l|}{ Smoking status (\%) } \\
\hline Never smoked & 28.2 & 27.8 \\
\hline Ever smoked & 61.2 & 72.2 \\
\hline Unknown & 10.5 & 0.0 \\
\hline \multicolumn{3}{|l|}{$\begin{array}{l}\text { Mean (SD) lung } \\
\text { function }\end{array}$} \\
\hline FVC (\% predicted) & $69.1(21.6)$ & $72.3(20.6)$ \\
\hline $\mathrm{FEV}_{1}(\%$ predicted $)$ & $72.7(23.3)$ & $73.7(18.9)$ \\
\hline \multicolumn{3}{|l|}{ Biopsy $(\%)^{\star}$} \\
\hline $\begin{array}{l}\text { Open lung } \\
\text { biopsy/autopsy }\end{array}$ & 9.6 & 53.6 \\
\hline Transbronchial biopsy & 32.5 & 15.3 \\
\hline None & 55.5 & 31.0 \\
\hline Unknown & 2.4 & 0.0 \\
\hline
\end{tabular}

* Distribution is significantly different between cohorts $(\mathrm{p}<0.01)$

addition, patients with interstitial lung diseases were identified from computerised billing records of all pulmonary clinics and hospitals in the county. For inclusion in the Registry patients had to have a physician's clinical or pathological diagnosis of an interstitial lung disease during the enrolment period, be 18 years of age or older, and reside within Bernalillo County. Patients who did not have biopsy samples taken were required to have documented clinical evidence (clinical history, physical examination and radiographic findings, pulmonary function tests) to support the diagnosis. Cases with only a radiographic diagnosis of an interstitial lung disease were excluded. During its four year enrolment period from 1 October 1988 to 30 September 1992 a total of 4520 patients were referred to the Registry and were reviewed: 3537 did not have an interstitial lung disease or had insufficient evidence to support the diagnosis, and 258 did not live in Bernalillo County or were younger than 18 years. Of 725 cases meeting enrolment criteria, 316 were prevalent and 409 were incident cases. Of the incident cases, 200

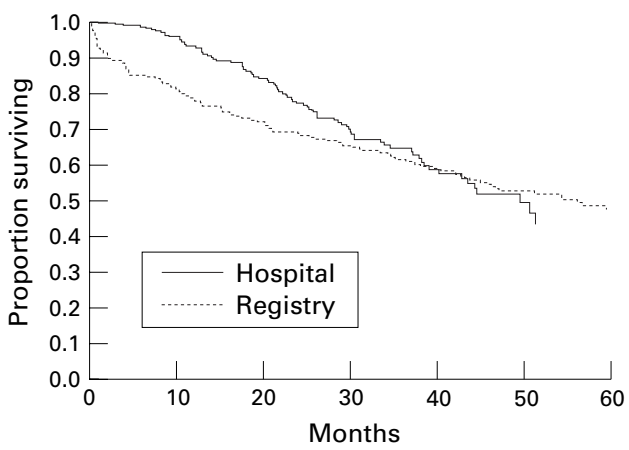

Figure 1 Kaplan-Meier estimates of survival for patients with idiopathic pulmonary fibrosis (IPF) in the hospital based cohort and in the New Mexico Interstitial Lung Disease Registry. Tests of equality over strata: $\log$ rank $\left(\chi^{2}\right.$ $=0.73, p=0.39)$; Wilcoxon $\left(\chi^{2}=5.35, p=0.02\right)$. had a specific interstitial lung disease diagnosis such as sarcoidosis or asbestosis, and the remaining 209 patients with IPF are included as the study cohort.

Chest radiographs taken near the time of diagnosis were obtained whenever available and scored for profusion by a certified "B" reader (DBC) using the International Labor Organization classification system. Profusion abnormalities that scored $1 / 2$ or lower were designated as "mild", those from $2 / 1$ to $2 / 3$ as "moderate", and those of $3 / 2$ or greater as "severe". All radiographs were read without prior knowledge of the clinical history.

Pulmonary function tests obtained near the time of diagnosis were abstracted from medical records. Reductions in the forced vital capacity (FVC) and forced expiratory volume in one second $\left(\mathrm{FEV}_{1}\right)$ of less than $80 \%$ of predicted were designated as "moderate" and values of less than $60 \%$ of predicted were designated as "severe". To examine the relationship between airway obstruction and survival in IPF, patients were divided into three categories: those with an $\mathrm{FEV}_{1}$ of more than $80 \%$ predicted were "normal", those with an $\mathrm{FEV}_{1}$ of less than $80 \%$ predicted and an $\mathrm{FEV}_{1} / \mathrm{FVC}$ ratio of less than 0.75 were designated as "obstructed"; and those with an $\mathrm{FEV}_{1}$ of less than $80 \%$ predicted and an $\mathrm{FEV}_{1} / \mathrm{FVC}$ ratio of more than 0.75 were designated as "restricted".

Detailed cigarette smoking histories were available only for patients who had personal interviews; the remainder were classified as "ever smokers" or "never smokers" based on medical records. Patients who reported using cigarettes for a total of less than six months during their lifetimes were classified as never smokers. Patients for whom smoking exposure could not be quantified were listed as unknown. Because only six patients in the Registry continued to smoke after the time of their diagnosis, current and former smokers were analysed together.

During case ascertainment for the Registry it was noted that patients with IPF were usually assigned the diagnostic billing codes pulmonary fibrosis (ICD-9, 515), idiopathic or interstitial pulmonary fibrosis (ICD-9, 516.3), or interstitial or primary pneumonitis (unspecified ICD-9 codes). To investigate whether the differences in diagnostic codes had any influence on survival, we included the coding groups in the survival analyses.

The vital status of each patient in the Registry was confirmed by follow up contact with patients, their families, or their physicians. For those whose vital status could not be determined from these sources, we searched the New Mexico Bureau of Vital Statistics and the National Death Index. As of 15 August 1995, a total of 114 patients $(54.5 \%)$ were deceased. All patients not confirmed as deceased at that date were assumed to be alive. A review of the causes of death and the accuracy of death certificate diagnoses in the New Mexico Interstitial Lung Disease Registry has been previously published. ${ }^{17}$ 
Table 2 Relative hazard (RH) comparing New Mexico ILD Registry with hospital based cohort from Cox's proportional hazards model adjusted for age, ethnic group, and sex

\begin{tabular}{ll}
\hline Months after diagnosis & $R H(95 \%$ CI $)$ \\
\hline $0-6$ & $6.32(2.19$ to 18.22$)$ \\
$6-18$ & $0.72(0.41$ to 1.27$)$ \\
$18-30$ & $0.35(0.19$ to 0.66$)$ \\
$30-42$ & $0.36(0.17$ to 0.79$)$ \\
42 or more & $0.38(0.15$ to 0.98$)$ \\
\hline
\end{tabular}

IPF CASE-CONTROL STUDY

To compare the survival of the patients with IPF identified in the New Mexico ILD Registry with those patients identified at referral hospitals, we examined the survival of 248 patients with IPF who participated in a multicentre case-control study. These patients were diagnosed between January 1989 and July 1993 at 16 different institutions located in 15 states. Details of the study methods and patient characteristics of the IPF case-control study have been previously published. ${ }^{16}$ Patients who had the diagnosis of IPF made without lung biopsies were required to have documented symptoms of cough or dyspnoea, bilateral crackles on chest auscultation, and bilateral reticular or reticulonodular infiltrates on chest radiography. Survival for each patient in the case-control study was determined from the time of diagnosis, and survival status was determined by follow up with the patient or a family member. For those whose vital status could not be determined from these sources, we searched the National Death Index. All persons who were not confirmed as deceased at 31 December 1993 were assumed to be alive.

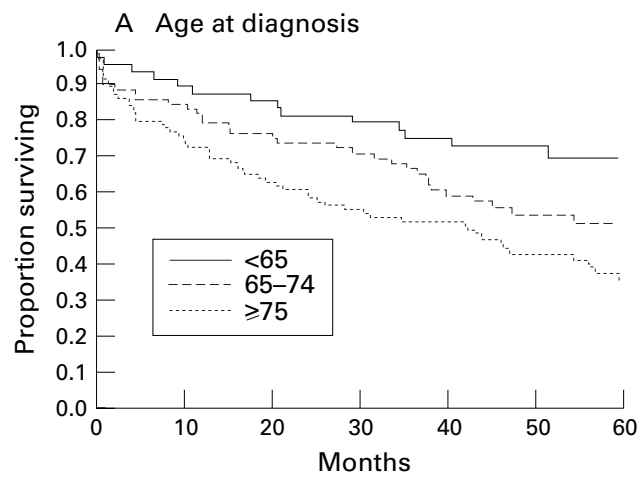

C FVC \% Predicted

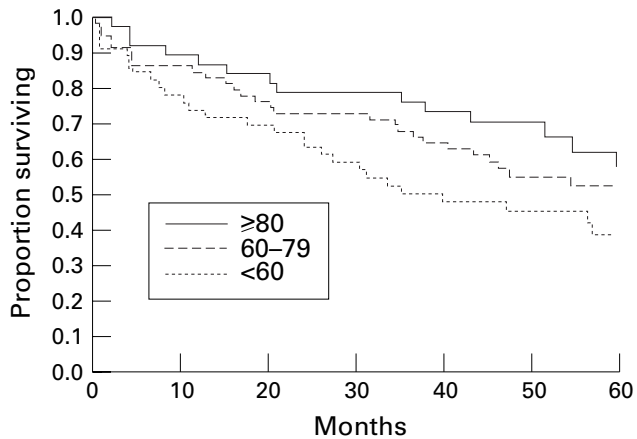

STATISTICAL ANALYSIS

All calculations were performed using SAS procedures..$^{18}$ The duration of survival from the date of diagnosis was determined for each patient. Survival distributions were computed using the Kaplan-Meier life table method and differences in survival between the groups of patients with clinical factors of interest were compared using log rank and Wilcoxon tests.

The Cox proportional hazards model was used to compare the survival of the patients on the Registry with those from the case-control study, and to determine the effect of various factors on survival in the Registry cohort. These results are expressed as the relative hazard for death among those who had or were exposed to a factor of interest compared with those who did not have or were not exposed to the factor. The proportional hazards assumption for each covariate in the model was evaluated using $\log (-\log )$ plots and Schonfeld's goodness-of-fit test. ${ }^{19}$ The relative hazard comparing death in the two cohorts was found to vary over time so the relative hazard was calculated for five separate time intervals. Two-way interactions between all variables in the final models were tested and found to be insignificant.

The relative survival rates of patients with IPF in the New Mexico ILD Registry and in the case-control study were computed using the 1980 United States census life tables. ${ }^{20}$ The expected survival in the Registry and in the case-control study was determined by matching each patient to the census data by age, sex, and ethnicity (non-Hispanic white, Hispanic, or other). The relative survival was computed

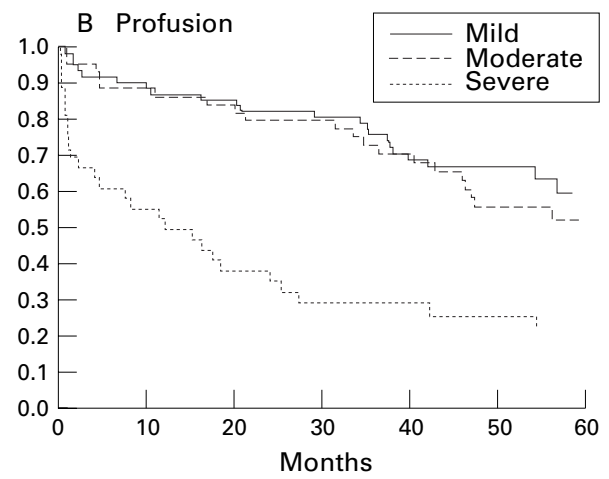

D Sex

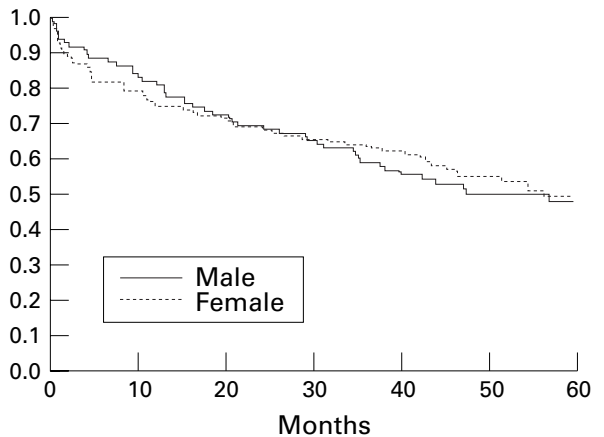

Figure 2 Kaplan-Meier estimates of survival for patients with idiopathic pulmonary fibrosis (IPF) in the New Mexico Interstitial Lung Disease Registry by (A) patient age (in years), (B) degree of chest radiographic profusion abnormality, (C) percentage predicted forced vital capacity, and (D) patient sex. 
Table 3 Observed, expected and relative survival of patients with idiopathic pulmonary fibrosis (IPF) in the New Mexico ILD Registry and hospital based case-control study cohorts

\begin{tabular}{lccl}
\hline $\begin{array}{l}\text { Years after } \\
\text { diagnosis }\end{array}$ & $\begin{array}{l}\text { Observed } \\
\text { survival }\end{array}$ & $\begin{array}{l}\text { Expected } \\
\text { survival }\end{array}$ & $\begin{array}{l}\text { Relative survival } \\
\text { (95\% CI) }\end{array}$ \\
\hline Patients in the New Mexico ILD Registry \\
1 & 0.78 & 0.95 & $0.82(0.76$ to 0.88$)$ \\
2 & 0.69 & 0.89 & $0.77(0.67$ to 0.84$)$ \\
3 & 0.61 & 0.84 & $0.73(0.65$ to 0.81$)$ \\
4 & 0.52 & 0.79 & $0.66(0.57$ to 0.75$)$ \\
5 & 0.47 & 0.74 & $0.64(0.54$ to 0.74$)$ \\
Patients in the hospital based cohort: & \\
1 & 0.91 & 0.98 & $0.93(0.89$ to 0.96$)$ \\
2 & 0.76 & 0.96 & $0.80(0.74$ to 0.86$)$ \\
3 & 0.65 & 0.94 & $0.69(0.62$ to 0.77$)$ \\
4 & 0.52 & 0.91 & $0.57(0.48$ to 0.67$)$ \\
5 & 0.45 & 0.89 & $0.50(0.38$ to 0.63$)$ \\
\hline
\end{tabular}

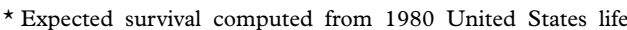
tables specific for age, race, and sex.

as the observed survival divided by the expected survival in the respective groups.

\section{Results}

The mean age of patients with IPF in the New Mexico ILD Registry was significantly greater than that of the hospital referral cohort $(71.7$ years versus $60.6, \mathrm{p}<0.01)$, and the average duration of follow up among survivors was greater in the Registry cases ( 57.3 versus 29.8 months, $\mathrm{p}<0.01)$. There was a slightly higher proportion of women in the Registry cohort, although the difference was not statistically significant (table 1). The ethnic background of
Registry patients was representative of the ethnic population distribution of Bernalillo County $(55.9 \%$ non-Hispanic white, $36.2 \%$ Hispanic, 3.4\% Native American, 2.7\% African American, $1.8 \%$ other non-whites; 1990 US Census). The proportion of smokers and the mean \% predicted FVC and $\mathrm{FEV}_{1}$ at the time of diagnosis were similar in each cohort. Only $42 \%$ of patients with IPF in the Registry had lung biopsy samples taken compared with $69 \%$ of patients in the hospital based cohort. Patients of less than 65 years of age at the time of diagnosis were significantly more likely to have lung biopsy samples taken than those aged 65 or older in both cohorts $(p<0.01)$.

The Kaplan-Meier survival plots for the Registry and hospital based cohorts are shown in fig 1 . The median survival times of patients with IPF in the Registry and case-control cohorts were similar (4.2 years and 4.1 years, respectively). Although the difference between the survival curves was not significant by the log-rank method, it was statistically significant by the Wilcoxon method which emphasises differences in the beginning of the survival curve.

Cox proportional hazards models adjusting for differences in age, ethnic group, and sex were used to estimate the relative hazard of death in the Registry to the hospital-based cohort at various time intervals after diagnosis (table 2). Within the first six months of

Table 4 Summary statistics for life table analysis of survival of patients with idiopathic pulmonary fibrosis (IPF) in the New Mexico ILD Registry

\begin{tabular}{|c|c|c|c|c|}
\hline Factor & Category & No. & $\begin{array}{l}\text { Five year survival } \\
(95 \% \mathrm{CI})\end{array}$ & $\begin{array}{l}p \text { value for log } \\
\text { rank test }\end{array}$ \\
\hline Age at diagnosis & $\begin{array}{l}\text { Under } 65 \text { years } \\
65-74 \text { years } \\
75 \text { years or older }\end{array}$ & $\begin{array}{l}47 \\
70 \\
92\end{array}$ & $\begin{array}{l}68.8(55.0 \text { to } 82.6) \\
50.7(38.4 \text { to } 63.0) \\
34.5(23.6 \text { to } 45.3)\end{array}$ & 0.001 \\
\hline Chest radiographic profusion & $\begin{array}{l}\text { Mild } \\
\text { Moderate } \\
\text { Severe }\end{array}$ & $\begin{array}{l}68 \\
45 \\
24\end{array}$ & $\begin{array}{l}53.0(39.5 \text { to } 66.4) \\
48.6(33.2 \text { to } 64.0) \\
23.8(6.3 \text { to } 41.3)\end{array}$ & 0.008 \\
\hline FVC $(\% \text { predicted })^{\star}$ & $\begin{array}{l}>80 \\
60-80 \\
<60\end{array}$ & $\begin{array}{l}38 \\
59 \\
46\end{array}$ & $\begin{array}{l}55.6(36.9 \text { to } 74.4) \\
49.1(35.2 \text { to } 63.2) \\
33.7(18.2 \text { to } 49.2)\end{array}$ & 0.124 \\
\hline $\mathrm{FEV}_{1}(\%$ predicted $)$ & $\begin{array}{l}>80 \\
60-80 \\
<60\end{array}$ & $\begin{array}{l}53 \\
49 \\
41\end{array}$ & $\begin{array}{l}56.1(41.4 \text { to } 70.8) \\
50.5(35.6 \text { to } 65.4) \\
37.4(20.8 \text { to } 54.1)\end{array}$ & 0.103 \\
\hline Airflow & $\begin{array}{l}\text { Normal } \\
\text { Obstructed } \\
\text { Restricted }\end{array}$ & $\begin{array}{l}53 \\
33 \\
57\end{array}$ & $\begin{array}{l}56.1(41.4 \text { to } 70.8) \\
46.1(26.6 \text { to } 65.5) \\
43.3(29.7 \text { to } 56.9)\end{array}$ & 0.417 \\
\hline Duration of symptoms prior to diagnosis & $\begin{array}{l}<12 \text { months } \\
\geqslant 12 \text { months }\end{array}$ & $\begin{array}{r}152 \\
21\end{array}$ & $\begin{array}{l}50.0(36.5 \text { to } 53.5) \\
70.7(50.9 \text { to } 90.5)\end{array}$ & 0.028 \\
\hline Sex & $\begin{array}{l}\text { Women } \\
\text { Men }\end{array}$ & $\begin{array}{r}94 \\
115\end{array}$ & $\begin{array}{l}47.6(36.8 \text { to } 58.4) \\
47.5(37.5 \text { to } 57.5)\end{array}$ & 0.915 \\
\hline Smoking & $\begin{array}{l}\text { Never smoked } \\
\text { Ever smoked }\end{array}$ & $\begin{array}{r}59 \\
128\end{array}$ & $\begin{array}{l}44.1(30.9 \text { to } 57.3) \\
50.3(40.6 \text { to } 60.0)\end{array}$ & 0.250 \\
\hline Ethnic group & $\begin{array}{l}\text { Hispanic } \\
\text { Non-Hispanic White }\end{array}$ & $\begin{array}{r}48 \\
128\end{array}$ & $\begin{array}{l}39.9(25.5 \text { to } 54.2) \\
51.2(41.7 \text { to } 60.8)\end{array}$ & 0.139 \\
\hline Corticosteroids & $\begin{array}{l}\text { Not treated } \\
\text { Treated }\end{array}$ & $\begin{array}{r}114 \\
76\end{array}$ & $\begin{array}{l}52.7(43.0 \text { to } 62.3) \\
41.6(29.5 \text { to } 53.8)\end{array}$ & 0.292 \\
\hline Diagnostic code (ICD-9) & $\begin{array}{l}\text { IPF (516.3) } \\
\text { Pulmonary fibrosis (515) } \\
\text { Primary or interstitial pneumonitis }\end{array}$ & $\begin{array}{r}129 \\
56 \\
24\end{array}$ & $\begin{array}{l}46.4(37.0 \text { to } 55.8) \\
42.1(28.2 \text { to } 56.0) \\
66.7(47.8 \text { to } 85.5)\end{array}$ & 0.113 \\
\hline Biopsy & $\begin{array}{l}\text { Transbronchial } \\
\text { Open lung/autopsy } \\
\text { No biopsy }\end{array}$ & $\begin{array}{r}68 \\
20 \\
116\end{array}$ & $\begin{array}{l}52.9(40.1 \text { to } 65.7) \\
44.0(18.0 \text { to } 70.0) \\
45.8(36.1 \text { to } 55.5)\end{array}$ & 0.526 \\
\hline
\end{tabular}

* Comparison between $\%$ predicted $\mathrm{FVC}<60$ and $\%$ predicted $\mathrm{FVC}>60$, p value $=0.044$. 
Table 5 Cox's proportional hazards model for survival of patients with idiopathic pulmonary fibrosis (IPF) in the New Mexico ILD Registry

\begin{tabular}{|c|c|c|c|c|}
\hline Factor & Category & $R H^{\star}$ & $95 \% C I$ & pvalue $* *$ \\
\hline Age at diagnosis & $\begin{array}{l}\text { Under } 65 \text { years } \\
65-74 \text { years } \\
75 \text { years or older }\end{array}$ & $\begin{array}{l}1.00 \\
2.12 \\
2.74\end{array}$ & $\begin{array}{l}1.13 \text { to } 3.99 \\
1.49 \text { to } 5.06\end{array}$ & 0.006 \\
\hline Chest radiographic profusion & $\begin{array}{l}\text { Mild } \\
\text { Moderate } \\
\text { Severe }\end{array}$ & $\begin{array}{l}1.00 \\
1.29 \\
3.10\end{array}$ & $\begin{array}{l}0.73 \text { to } 2.28 \\
1.66 \text { to } 5.77\end{array}$ & 0.001 \\
\hline FVC (\% predicted) & $\begin{array}{l}>80 \\
60-79 \\
<60\end{array}$ & $\begin{array}{l}1.00 \\
1.23 \\
1.82\end{array}$ & $\begin{array}{l}0.64 \text { to } 2.37 \\
0.92 \text { to } 3.58\end{array}$ & 0.180 \\
\hline Duration of symptoms prior to diagnosis & $\begin{array}{l}<12 \text { months } \\
\geqslant 12 \text { months }\end{array}$ & $\begin{array}{l}1.00 \\
0.52\end{array}$ & 0.23 to 1.20 & 0.126 \\
\hline Sex & $\begin{array}{l}\text { Women } \\
\text { Men }\end{array}$ & $\begin{array}{l}1.00 \\
1.00\end{array}$ & 0.65 to 1.52 & 0.987 \\
\hline Cigarette smoking & $\begin{array}{l}\text { Never smoked } \\
\text { Ever smoked }\end{array}$ & $\begin{array}{l}1.00 \\
0.72\end{array}$ & 0.45 to 1.16 & 0.177 \\
\hline Ethnicity & $\begin{array}{l}\text { Non-Hispanic White } \\
\text { Hispanic } \\
\text { Other }\end{array}$ & $\begin{array}{l}1.00 \\
1.32 \\
0.95\end{array}$ & $\begin{array}{l}0.84 \text { to } 2.08 \\
0.41 \text { to } 2.12\end{array}$ & 0.469 \\
\hline Corticosteroids & $\begin{array}{l}\text { Not treated } \\
\text { Treated }\end{array}$ & $\begin{array}{l}1.00 \\
2.07\end{array}$ & 1.26 to 3.37 & 0.004 \\
\hline Diagnostic code (ICD-9) & $\begin{array}{l}\operatorname{IPF}(516.3) \\
\text { Pulmonary fibrosis (515) } \\
\text { Primary or interstitial pneumonitis }\end{array}$ & $\begin{array}{l}1.00 \\
1.43 \\
0.55\end{array}$ & $\begin{array}{l}0.91 \text { to } 2.26 \\
0.25 \text { to } 1.21\end{array}$ & 0.060 \\
\hline Biopsy & $\begin{array}{l}\text { Transbronchial } \\
\text { Open lung/autopsy } \\
\text { No biopsy }\end{array}$ & $\begin{array}{l}1.00 \\
1.79 \\
1.09\end{array}$ & $\begin{array}{l}0.83 \text { to } 3.83 \\
0.64 \text { to } 1.87\end{array}$ & 0.312 \\
\hline
\end{tabular}

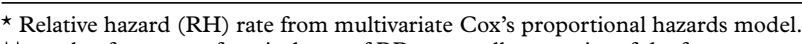

$\star \star \mathrm{p}$ value from test of equivalence of $\mathrm{RR}$ across all categories of the factor.

diagnosis the death rate was significantly greater among the patients in the Registry but, after 18 months, the death rate was significantly lower.

The survival of patients with IPF in the New Mexico ILD Registry was significantly less than the expected survival determined from the 1980 United States census life tables (table 3). The observed survival and the relative survival at one year after diagnosis were lower in the Registry cohort than in the case-control study cohort. However, by three years after diagnosis the relative survival in the case-control study cohort was poorer, while the observed survival in the two groups was very similar.

LIFE TABLE ANALYSIS OF PATIENTS WITH IPF IN THE NEW MEXICO ILD REGISTRY

Age at diagnosis was a strong determinant of survival for patients with IPF in the ILD Registry (fig 2, table 4). Severity of illness at diagnosis, as indicated by the degree of fibrosis on chest radiographs and the degree of impairment on spirometric testing, did not differ by age. Patients age 75 years or older were significantly less likely to have smoked ( $54.3 \%$ versus $79.3 \%$ ) and were also less likely to have been treated with corticosteroids $(28.1 \%$ versus $49.1 \%$ ) than patients in the other age groups.

Patients with severe profusion abnormalities on the chest radiograph had significantly reduced survival (fig 2 , table 4 ). The median survival for patients with severe profusion abnormalities was only 13.5 months compared with 62.7 months and 56.2 months for the mild or moderate profusion groups, respectively. Although there was a tendency for patients with severe radiographic abnormalities to also have abnormal spirometric values, the correlation between the degree of radiographic abnormality and the degree of spirometric impairment was weak (Spearman's $r=0.16, \mathrm{p}=$ 0.15).

Patients with IPF with severe reductions in FVC on routine spirometric testing also had poorer survival (fig 2, table 4 ). The median survival for patients with FVC of less than $60 \%$ of predicted was only 37.5 months compared with 64.7 months for patients with FVC of $60 \%$ of predicted or greater. The survival distributions by category of $\mathrm{FEV}_{1}$ were similar to those for FVC. Patients with restrictive or obstructive spirometry patterns had slightly reduced survival compared with those with normal spirometry; however, the differences were not significant.

Patients with symptoms related to IPF for more than 12 months prior to diagnosis had significantly better survival than those having symptoms for less than 12 months. However, because most patients reported having IPF symptoms for less than 12 months, the estimate for the five year survival for those with a longer duration of symptoms is imprecise (table 4). There were no significant differences in symptom duration by age, sex, ethnicity, smoking status, use of corticosteroid therapy, radiographic profusion abnormality, or impairment on spirometric testing.

Survival did not differ significantly according to sex, although there were sex differences in clinical presentation, diagnostic evaluation, and treatment (fig 2, table 4). Men were more likely than women to have moderate or severe 
profusion abnormalities on the chest radiograph at the time of diagnosis $(62.0 \%$ versus $34.6 \%)$ or to have had diagnostic biopsy samples taken $(49.1 \%$ versus $36.2 \%)$. Men were also more likely to have been treated with corticosteroids (44.2\% versus $33.8 \%$ ).

Persons who had ever smoked cigarettes tended to have better survival than those who had never smoked, although the difference was not significant (table 4). Ever smokers were significantly younger than never smokers, and a higher proportion of men than women had used cigarettes $(77.7 \%$ versus $55.7 \%)$. The prevalence of use of tobacco by age, sex, and ethnicity in the IPF Registry was similar to findings of a survey of the residents of Bernalillo County in 1979-1980. ${ }^{21}$ Ever smokers were also more likely to have received corticosteroid therapy $(49.6 \%$ versus $25.9 \%)$. There were no significant differences between the never smokers and ever smokers in terms of chest radiographic profusion, spirometric abnormalities, or symptom duration.

Other clinical factors which did not appear to be associated with survival by univariate analysis included ethnicity, corticosteroid treatment, diagnostic coding category, and history of biopsy (table 4). The Hispanic group was older than the non-Hispanic white group at the time of diagnosis ( 74.9 versus 70.5 years) but there were no differences in the degree of chest radiographic profusion abnormalities or spirometric impairment between the two groups. Patients with IPF with the billing codes pulmonary fibrosis (ICD-9, 515) or idiopathic or interstitial pulmonary fibrosis (ICD-9, 516.3) tended to be older, have a longer duration of symptoms, and have more radiographic abnormality than those coded as interstitial or primary pneumonitis, but the differences did not reach significance.

PROPORTIONAL HAZARDS MODELLING FOR SURVIVAL OF IPF PATIENTS IN THE REGISTRY The Cox's proportional hazards model was used to estimate the relative risk associated with each survival factor while adjusting for all other factors. In these analyses the risk of death was significantly higher for patients with advanced age or severe profusion abnormalities on the chest radiograph (table 5). As noted in the life table analysis, those with severe reduction in FVC had poorer survival than the other groups although the differences among the three groups did not reach statistical significance. A history of corticosteroid treatment, which was not significant in the life table analysis, was associated with a significantly increased risk of death in the proportional hazards model. Patients with a duration of symptoms of 12 months or more prior to diagnosis and those diagnosed with primary pneumonitis also tended to have better survival. Sex, cigarette smoking, ethnicity, and biopsy history were not associated with a significantly increased relative risk of death. Terms for obstructive lung disease and restrictive lung disease were not significant when included in the model.

\section{Discussion}

Although the median survival of patients with IPF in the population based Registry was similar to that of the cohort of patients seen at referral hospitals, we found substantial differences in mean age and in adjusted survival between the two cohorts. The mean age of Registry patients was 71.7 years, which is similar to the mean age of the British Thoracic Society's national registry of patients with cryptogenic fibrosing alveolitis $(\mathrm{CFA})^{22}$; the mean age of the referral hospital cohort was 60.6 years which is similar to the mean ages reported from previous referral hospital cohorts. ${ }^{4-14}$ After adjusting for age, sex, and ethnic group, patients in the Registry had a higher mortality within six months of diagnosis than the cohort of IPF patients seen at referral hospitals, but better survival after 18 months. These findings suggest the following: (1) the average age of patients with IPF in the general population is much greater than previously reported from case series; (2) the adjusted survival of patients with IPF in the general population is different from that of referral hospital populations; and (3) selection biases may affect the survival experience of referral hospitals.

Survival among patients in the Registry with IPF was primarily related to the patient's age at the time of diagnosis and to indices of disease progression, including severe chest radiographic profusion abnormalities and severe lung function impairment. The median survival among IPF patients in the Registry from the date of diagnosis was 4.2 years, similar to the median survival durations reported in hospital based reports ${ }^{4-68914}$ and to that of the cohort of IPF patients seen at referral hospitals. The relative survival of IPF patients in the Registry at five years compared with the expected survival determined from census data was $63.7 \%$ (95\% CI 53.8 to 73.6 ). A history of treatment with corticosteroids was associated with increased risk of death in the proportional hazards model. This result must be interpreted with caution: the New Mexico ILD Registry was not designed as an intervention study and patients were treated only at the discretion of their personal physician. Patient sex, ethnicity, tobacco use, and history of biopsy were not significant predictors of survival in the Registry.

IPF is considered to arise from a disease process in which a cellular inflammatory response to an unknown stimulus eventually results in diffuse and permanent pulmonary fibrosis. ${ }^{23}$ Several studies have found that patients with histological evidence of active inflammation are more likely to improve clinically with treatment ${ }^{56910}$ and also to have better survival. ${ }^{459-1114}$ However, reports from investigations of the prognosis of patients with IPF that examined factors other than tissue histology are inconsistent and even conflicting. Bronchoalveolar lavage (BAL) cell counts have been reported as predictive of treatment response and disease progression in IPF ${ }^{152425}$ but, after adjusting for other clinical factors, BAL cell counts lose their prognostic significance. $^{826}$ Patients with IPF with a 
reduced FVC are more likely to have active alveolitis ${ }^{27}$ and are more likely to improve with treatment, ${ }^{1528}$ but they are also more likely to have reduced survival. ${ }^{9}{ }^{12} 15$ Other factors that have shown inconsistent or conflicting associations with progression and survival in IPF include male $\operatorname{sex}^{4-68}$ age at diagnosis, ${ }^{4-8}$ and duration of symptoms prior to diagnosis. ${ }^{6910}$ These discrepancies among IPF studies have several possible explanations. Because of the variable clinical presentations of IPF, the potential exists for large differences in the mean patient age, severity of illness at presentation, and rate of disease progression among study groups. In addition, differences in clinical diagnostic criteria and the variability in pathological diagnosis and grading may result in disease misclassification. There is also evidence that the presentation of IPF may be affected by patient age and smoking status, ${ }^{27}$ which is also suggested in our study. The effects of competing causes of death such as coronary artery disease and cancer have not been adequately accounted for in published studies, in spite of the fact that IPF most often afflicts the elderly, and that many people with IPF die of unrelated diseases. ${ }^{17}$ Data from the UK and from our Registry also suggest that referral patterns and management differences could result in a biased survival experience at pulmonary referral centres. ${ }^{29} 30$

Of the 209 patients with IPF in the Registry cohort, only $42 \%$ had any type of lung biopsy sample taken compared with the 50-100\% biopsy rates reported in survival studies from referral centres. ${ }^{4-15}$ This may have resulted in disease misclassification in the Registry, with some patients with IPF having other types of interstitial lung diseases with different survival characteristics. Because only a few patients had biopsy samples taken, we also could not examine tissue cellularity as a prognostic factor. Nevertheless, any errors in the survival estimates due to disease misclassification and confounding resulting from the lack of biopsy data are likely to be small for several reasons: (1) a clinical diagnosis of IPF in the Registry was associated with a poor median survival quite similar to that of patients with IPF from the hospital based cohort (4.2 years and 4.1 years, respectively); (2) the mean percentage predicted FVC and $\mathrm{FEV}_{1}$ of the Registry group at the time of diagnosis was not different from that of the hospital cohort; (3) $96 \%$ of patients in the Registry were diagnosed and treated by pulmonologists who applied the same diagnostic criteria as those used in previous IPF studies when biopsy samples were not taken; and (4) survival in the Registry was not related to a history of biopsy. The limited use of biopsy, which has also been seen in the British Thoracic Society CFA registry, may be due to scepticism about the utility of invasive diagnostic procedures to diagnose a disease with a generally limited response to treatment. ${ }^{22} 30$

We were unable to examine the relationship between response to IPF treatment and survival. Clinical improvement with corticosteroid therapy has been associated with an improved prognosis, $56913-15$ although it is not known whether corticosteroids actually affect the natural history of the disease. ${ }^{23}$ Because the majority of the IPF patients in the Registry were older, had evidence of advanced disease at presentation, and were not treated, it is unlikely that data about treatment response would have significantly altered the overall survival analysis.

Transfer factor (diffusion capacity) was not available for a high proportion of patients in both cohorts, so it was not used for analysis. The reasons for its inconsistent use are not clear. In the ILD Registry transfer factor was often not measured in subjects with severe radiographic or spirometric impairment, possibly because the diagnosis was more obvious in these patients, or because it is a technically difficult test in those with severely limited lung function.

We found that survival among those in the Registry, ascertained from 1988-1992, was similar to earlier reports in the literature with case ascertainments in the 1960s and 1970s. For example, the mean survival in the Edinburgh Hospital review was 47.4 months $^{9}$ and the median survival in the Brompton Hospital series was 4.5 years. ${ }^{4}$ Thus, in spite of a changing approach to treating IPF, survival has not improved. ${ }^{30}$ These results emphasise the need for clinical trials to determine optimal treatments of IPF and to give physicians information on the benefits and risks of treatment.

The authors wish to thank Rita Elliott for her editorial review and Sally Goehring for her clerical assistance.

Supported by National Research Service Award 5T32H207733 (DWM), HL-40587 (DBC), and HL43153 (JMS) from the Division of Lung Diseases, National Heart, Lung and Blood Institute, National Institutes of Health (NIH).

1 Panos RJ, Mortenson RL, Niccoli SA, et al. Clinical deterioration in patients with idiopathic pulmonary fibrosis: causes and assessment. Am F Med 1990;88:396-404.

2 Coultas DB, Zumwalt RE, Black WC, et al. The epidemiology of interstitial lung diseases. Am F Respir Crit Care Med 1994;150:967-72.

3 Coultas DB. Epidemiology of idiopathic pulmonary fibrosis. Semin Respir Med 1993;14:181-96.

4 Turner-Warwick M, Burrows B, Johnson A. Cryptogenic fibrosing alveolitis: clinical features and their influence on fibrosing alveolitis: clinical features

5 Turner-Warwick M, Burrows B, Johnson A. Cryptogenic fibrosing alveolitis: response to corticosteroid treatment and its effect on survival. Thorax 1980;35:593-9.

6 Tukiainen P, Taskinen E, Holsti P, et al. Prognosis of cryptogenic fibrosing alveolitis. Thorax 1983;38:349-55.

7 Raghu G, Depaso WJ, Cain K, et al. Azathioprine combined with prednisone in the treatment of idiopathic pulmonary fibrosis: a prospective double-blind, randomized, placebocontrolled trial. Am Rev Respir Dis 1991;144:291-6.

8 Schwartz DA, Helmers RA, Galvin JR, et al. Determinants of survival in idiopathic pulmonary fibrosis. Am ₹ Respir Crit Care Med 1994;149:450-54.

9 Stack BHR, Choo-Kang YFJ, Heard BE. The prognosis of cryptogenic fibrosing alveolitis. Thorax 1972;27:535-42.

10 Winterbauer RH, Hammar SP, Hallman KO, et al. Diffuse interstitial pneumonitis: clinicopathologic correlations in 20 patients treated with prednisone/azathioprine. $A m \mathcal{F}$ 20 patients treated with
Med 1978;65:661-72.

11 Wright PH, Heard BE, Steel SJ, et al. Cryptogenic fibrosing alveolitis: assessment by graded trephine lung biopsy histology compared with clinical, radiographic, and physiological features. Br $\mathcal{F}$ Dis Chest 1981;75:61-70.

2 Johnson MA, Kwan S, Snell NJC, et al. Randomized controlled trial comparing prednisone alone with cyclophosphamide and low dose prednisolone in combination in cryptogenic fibrosing alveolitis. Thorax 1989;44:280-8.

13 Hanson D, Winterbauer RH, Kirtland SH, et al. Changes in pulmonary function test results after 1 year of therapy as predictors of survival in patients with idiopathic pulmonary fibrosis. Chest 1995;108:305-10.

14 Carrington CB, Gaensler EA, Coutu RE, et al. Natural history and treated course of usual and desquamative interstitial pneumonia. $N$ Engl f Med 1978;298:801-9.

15 Rudd RM, Halsam PL, Turner-Warwick M. Cryptogenic fibrosing alveolitis: relationships of pulmonary physiology fibrosing alveolitis: relationships of pulmonary physiology
and bronchoalveolar lavage to response to treatment and and bronchoalveolar lavage to response to
prognosis. Am Rev Respir Dis 1981;124:1-8. 
16 Baumgartner KB, Samet JM, Stidley CA, et al and collaborating centers. Cigarette smoking: a risk factor for idiopathic pulmo

17 Coultas DB, Hughes MP. Accuracy of mortality data for interstitial lung diseases in New Mexico, USA. Thorax 1996;51:717-20.

18 SAS/STAT User's Guide, Version 6, Fourth Edition. Cary, North Carolina: SAS Institute Inc, 1989.

19 Schonfeld D. Partial residuals for the proportional hazards model. Biometrika 1982;69:51-5.

20 Shambaugh EM, Young JL, Zippin C, et al. SEER Program, Cancer Statistics Branch, National Cancer Institute: Self-instructional Manual for Cancer Registrars; Book 7 - Statistics and Epidemiology for Cancer Registrars. United States Department of Health and Human Services, National Institutes of Health publication \#94-3766, 1994.

21 Samet JM, Schrag SD, Howard CA, et al. Respiratory disease in a New Mexico population sample of Hispanic and non-Hispanic whites. Am Rev Respir Dis 1982;125:152-7.

22 Johnston IDA, Prescott RJ, Chalmers JC, et al. British Thoracic Society study of cryptogenic fibrosing alveolitis: current presentation and initial management. Thorax 1997 52:38-44.

23 Hunninghake GW, Kalica AR. Approaches to the treatment of pulmonary fibrosis. Am f Respir Crit Care Med 1995;151 915-8.
24 Watters LC, Schwarz MI, Cherniack RM, et al. Idiopathic pulmonary fibrosis: pretreatment bronchoalveolar lavage cellular constituents and their relationships with lung histopathology and clinical response to therapy. Am Rev Respir Dis 1987;135:696-704.

25 Turner-Warwick M, Halsam PL. The value of serial bronchoalveolar lavages in assessing the clinical progress of patients with cryptogenic fibrosing alveolitis. Am Rev Respir Dis 1987;135:26-34

26 Schwartz DA, Van Fossen DS, Davis CS, et al. Determinants of progression in idiopathic pulmonary fibrosis. $A m \mathcal{F}$ Respir Crit Care Med 1994;149:444-9.

27 Cherniack RM, Colby TV, Flint A, et al. Correlation of structure and function in idiopathic pulmonary fibrosis. Am 7 Respir Crit Care Med 1995;151:1180-8.

28 van Oortegem K, Wallaert B, Marquette $\mathrm{CH}$, et al. Determinants of response to immunosuppressive therapy in idiopathic pulmonary fibrosis. Eur Respir $\mathcal{F}$ 1994;7: 1950-7.

29 Johnston IDA, Gomm SA, Kalra S, et al. The management of cryptogenic fibrosing alveolitis in three regions of the United Kingdom. Eur Respir f 1993;6:891-3.

30 Mapel DW, Samet JM, Coultas DB. Corticosteroids and the treatment of idiopathic pulmonary fibrosis: past, present, and future. Chest 1996;110:1058-67. 